The definitive version of this paper is available at https://www.mrs.org.uk/ijmr_article/article/111407 


\title{
The Impact of Word of Mouth on Intention to Purchase Currently Used and Other Brands
}

\begin{abstract}
We measure how the impact of positive and negative word of mouth (PWOM, NWOM) is related to the receiver's intention to purchase brands, using shift in the intention to purchase as the measure of impact. We distinguish between currently used and other brands and find that PWOM has more impact, and NWOM less impact, when these forms of advice are on the current brand. The PWOM effect persists among those who are disinclined to rebuy their current brand so it is not based on preference. Similarly, the NWOM effect is not enhanced when respondents are disinclined to repurchase their current brand. To explain this phenomenon, we suggest that the current brand is better understood, making it easier for customers to accept PWOM and reject NWOM on it, irrespective of preference. This work, by showing that the response to WOM is relatively independent of preference, also indicates that bias based on preference may be a limited hazard in survey responses about WOM.

When account is taken of the relative frequency of WOM on current and other brands, PWOM has twice as much effect on customer acquisition as customer retention, while NWOM has over four times as much effect in deterring the acquisition of new buyers as it has on deterring customer retention. This evidence contributes to our understanding of how WOM acts to both retain and acquire customers.
\end{abstract}

\section{Introduction}

\section{The impact of WOM}

Word of mouth (WOM) has a strong effect on purchase; Keaveney (1985) notes that 50 per cent of service provider replacements rest on recommendation and the Keller Fay Agency (2014) finds that one in eight recommendations results in a sale. These strong effects make it worthwhile to study the factors associated with the impact of WOM. Two factors that may affect the impact of WOM are brand preference and brand knowledge. We study the effect of brand preference by relating this variable to the intention to purchase/repurchase the brand. We infer the effect of knowledge by comparing responses relating to the current brand with those relating to other brands.

In this work, we examine the impact of both positive and negative WOM (PWOM, NWOM). Impact is measured as a change in the purchase intention from before to after receiving WOM. We assume that, generally, experience has cognitive effects, making a 
consumer more knowledgeable about their current brand. Normally, experience will be associated with preference but, exceptionally, respondents will be disinclined to repurchase their current brand and inclined to purchase another. The contribution of preference is identified by comparing the impact of WOM on those who are likely and those who are unlikely to (re)purchase a brand. The effect of brand knowledge is assessed by comparing the impacts of PWOM and NWOM on current and other brands.

This work makes a number of contributions. First, by teasing out the contribution of factors associated with the impact of WOM, it helps us to answer specific questions about WOM and more general questions about the way in which people react to influence. This is of interest to academic researchers who seek to explain how communications have influence, and to practitioners who want to anticipate the effect of communications. The work also casts light on the way in which consumer responses may, or may not, be biased, which is of interest to both academic and commercial researchers. A further contribution is to indicate how PWOM and NWOM assist customer acquisition and retention; this informs the ongoing debate on the best focus for promotional expenditure.

\section{Review}

\section{Preference}

Only one study by East, Hammond, and Lomax (2008) has compared the effect of WOM on the receiver's current brand with its effect on other brands; in this study, PWOM had more, and NWOM less, impact in changing the probability of purchase of the current brand than it did in changing the probability of purchase of other brands. This effect may be seen as unsurprising since those who prefer a brand are likely to be more open to positive information on the brand and less open to negative information. Such an effect might occur as an outcome of the affect heuristic whereby stimuli that are seen as good are used to direct more automatic decision making (Slovic, Finucane, Peters and MacGregor, 2002).

Alternatively, the effect may be related to greater knowledge of the current brand. The East et al. (2008) findings were reported as an aggregate effect and do not distinguish between the effects of preference and knowledge. If we disaggregate the observed shifts in purchase probability and express these as a function of the prior probability of purchase (i.e. before the WOM was received, hereafter PPP), we can test the preference explanation further. A proportion of current users of a brand will no longer prefer it and will express a low intention of repurchasing it. These people should be less open to PWOM on the brand if preference affects impact. At the other end of the range, greater preference should be associated with 
more impact. This suggests a curvilinear response to both PWOM and NWOM. We may test this by first establishing the PPPs before receiving WOM on current and other brands and then measuring the shifts in purchase probability for these different levels of PPP after WOM is received. A review of impact effects has suggested that WOM impact should be measured as a shift in intention that is proportional to the change that is possible (East et al. 2016); on this basis, a shift from 0.2 probability of purchase to 0.6 (that is, 0.4 out of a potential 0.8 ) would be the same impact as a shift from 0.4 to 0.7 (that is, 0.3 out of a potential 0.6). This would mean that a response that is linear with respect to PPP would indicate no effect of preference. If a curvilinear effect is not observed, we must look to other factors that affect the impact of WOM on the current brand and a likely candidate here is brand knowledge, since there is likely to be a difference in knowledge about the current brand and other brands.

\section{Knowledge of the brand}

Greater experience of a brand should lead to more knowledge of its properties. Thus current brands are likely to be better understood than other brands. Such understanding assists interpretation of new information with PWOM being more accommodated and NWOM more often discounted after reference to known features of the brand. This type of information processing would be consistent with the East et al. (2008) evidence that PWOM had more and NWOM less impact in aggregate on current brands than other brands. Thus our research question is:

RQ1. Across the range of PPP, how much do (re)purchase probabilities shift when people receive PWOM and NWOM on their current brand and on other brands?

\section{A check on respondent bias}

There is methodological interest in this type of work. A major problem in WOM research has been the fallibility of the different methods of investigation and some researchers have tried to establish how reliable are the findings from surveys (e.g. East, Uncles, Romaniuk and Hand, 2013). Survey findings may reflect respondent bias and this seems particularly likely when the current brand is compared with other brands. For example, respondents may exaggerate the impact of PWOM and diminish the impact of NWOM on the intention to repurchase the current brand when intention is assessed by subsequent purchase. If we find no evidence of a preference effect in this work, we will have more confidence in survey data of this sort. 


\section{How does WOM contribute to customer acquisition and retention?}

Although WOM is normally seen as having an effect on new purchase, it may also play a role in brand retention. PWOM on a currently owned brand should encourage customers to repurchase this brand, while NWOM may deter them from repurchase. Relationship marketers have emphasised methods designed to increase customer retention while normal customer acquisition continues. For example, Reichheld and Teal (1996), argue that resources spent on promoting customer retention are usually better value because of the greater return from established customers and the cheapness of implementing retention methods. However, the claimed advantages of customer retention have been questioned (e.g., Dowling and Uncles 1997, Reinartz and Kumar 2000, East, Hammond and Gendall 2006). Furthermore, research indicates that brands grow primarily by securing new customers rather than getting existing customers to buy more (Ehrenberg, Uncles and Goodhardt 2004, Sharp 2010, Riebe, Wright, Stern and Sharp 2014, Romaniuk, Dawes and Nenycz-Thiel 2014, Romaniuk and Sharp 2016). On the basis of this evidence, these authors have argued that brand growth is best achieved by methods that focus on raising customer acquisition. In this debate, we need to distinguish two different questions. One is the scale of customer growth offered by different methods and the other is the costs associated with each method. Here, we deal only with the former.

To turn these various claims into effective strategy, we need to know the ratio of effects on customer acquisition and retention produced by different interventions. This is usually not clear. For example, incentivized referral may have an effect on the person doing the referring (Garnefeld, Eggert, Helm and Tax, 2013), confirming their future purchasing, as well as on the person who is encouraged to switch by the referral, but we do not know the relative effects here ${ }^{1}$. Similarly, advertising may nudge existing customers toward more frequent purchase as well as securing new customers but we lack systematic evidence on this. Thus, it is worthwhile to assess the relative contribution of PWOM and NWOM to acquisition and retention. To do this, we compute the change in purchase intention among those who are currently non-users, weight this by their number, and then repeat this computation for current users. The ratio of these two computations for PWOM and NWOM provides an answer our second research question.

\footnotetext{
${ }^{1}$ Chandon, Morwitz, and Reinhartz (2005) show that measurement of a person's purchase intention raises the likelihood of later purchase and a similar reflexive effect might occur when a person recommends. Chawdhary and Dall'Olmo Riley (2015) conducted a simulation experiment which suggested that giving WOM enhances the sender's intention to give future WOM, which may raise customer acquisition.
} 
$R Q 2$. What is the relative effect of $P W O M$ and NWOM on acquiring and retaining customers?

Using a multi-category database, we examine responses to both PWOM and NWOM. We compare those receiving advice on their current brand with those receiving it on other brands and we relate this to the prior probability of purchase.

\section{Methodology}

Data

This research uses data from 18 category studies (listed in Table 1), conducted for other research on WOM. Fourteen of these studies were used by East et al. (2008) and obtained from them; we added four further studies (the last four shown in Table 1). All 18 studies recorded the respondent's current brand. In some cases, data for two studies were gathered in one survey (hence common response rates in Table 1). Later in the questionnaire, respondents were asked whether they had received PWOM on a brand in the category and, in the most recent case, which brand this was for. Then respondents were asked corresponding questions about the last case of NWOM. In repertoire categories, respondents were asked about their main brand, which was treated as the current brand. The impact of WOM was measured as a change in the intention to (re)purchase. Respondents were asked how likely they were to buy the brand before and after receiving PWOM/NWOM (using 10\% intervals on an 11-point scale). The first number was the prior probability of purchase (PPP) and the difference between the two numbers was the raw impact score.

For PWOM, this procedure gave 611 cases about the current brand and 1179 about other brands; for NWOM, the figures were 287 and 1091. In some cases, alternative responses in the questionnaire limited data gathering and there were omissions when the respondent did not own the brand in a specific product category or had not received WOM. 
Table 1. Studies used

\begin{tabular}{|c|c|c|c|c|c|}
\hline Category & Date & Method & Sample size & $\begin{array}{c}\text { Usable } \\
\text { response rate \% }\end{array}$ & Country \\
\hline Mobile phone airtime & 2005 & $\mathrm{DC}$ & 300 & 64 & UK \\
\hline Mobile phone handset & 2005 & DC & 300 & 64 & UK \\
\hline Luxury brands & 2005 & CS & 115 & 87 & UK \\
\hline Restaurant, Iranian in London & 2005 & DF & 200 & 45 & UK \\
\hline Computer & 2006 & DC & 220 & 80 & UK \\
\hline Coffee shop & 2006 & $\mathrm{DC}$ & 220 & 80 & UK \\
\hline Restaurant, ethnic & 2006 & $\mathrm{DP}+\mathrm{DI}$ & 300 & 30 & UK \\
\hline Hair colourant & 2006 & $\mathrm{DC}$ & 220 & 77 & Japan \\
\hline Current bank account & 2007 & DC & 250 & 65 & UK \\
\hline Camera & 2007 & DP & 300 & 27 & UK \\
\hline Mobile phone airtime & 2007 & $\mathrm{DC}$ & 250 & 86 & UK \\
\hline Camera & 2007 & DP & 300 & 27 & UK \\
\hline Mobile phone handset & 2007 & $\mathrm{DC}$ & 250 & 86 & UK \\
\hline Credit card & 2008 & DC & 250 & 65 & UK \\
\hline Skin care products & 2008 & I & 225 & na & S. Korea \\
\hline Fast food restaurants & 2009 & DI & 120 & 48 & UK \\
\hline Theatre and cinema & 2009 & DI & 160 & 76 & UK \\
\hline
\end{tabular}

* Methods of gathering data: DP is drop-off with free post back; DF is distribution via friends; DC is drop off and collect; CS is distribution and collection in coffee shop; DS is distribution in stores; DI is face-to-face distribution and collection by intercept, I is Internet.

\section{Analysis}

Table 2 shows the numbers of respondents at each PPP for PWOM and NWOM on their current brand and other brands (columns 2, 3, 6, and 7). Table 2 also shows the shifts in purchase probability in response to the WOM received. Note that NWOM tends to reduce the probability of purchase so the shifts are mostly negative though some end-scale effects occur with small shifts against the main direction. We calculated the average PPP for PWOM and NWOM; for PWOM, this is 0.55 for the current brand and 0.40 for other brands; for NWOM, these figures are 0.59 and 0.40 . Thus, for current brands, there is somewhat less scope for change in the purchase probability in response to PWOM and somewhat more scope for change in response to NWOM, compared with other brands. Despite this, PWOM has more, and NWOM less, impact on current brands. From the bottom row of Table 2, an impact ratio of $0.187 / 0.174$ is derived for PWOM, showing that it has 7 percent more overall impact on the current brand than on other brands. For NWOM, the analysis shows that there is 15 percent more impact from NWOM on other brands than the current brand $(-0.116 /-0.101)$. 
Table 2. Numbers of respondents and shifts in the probability of purchase by prior probability of purchase (PPP)

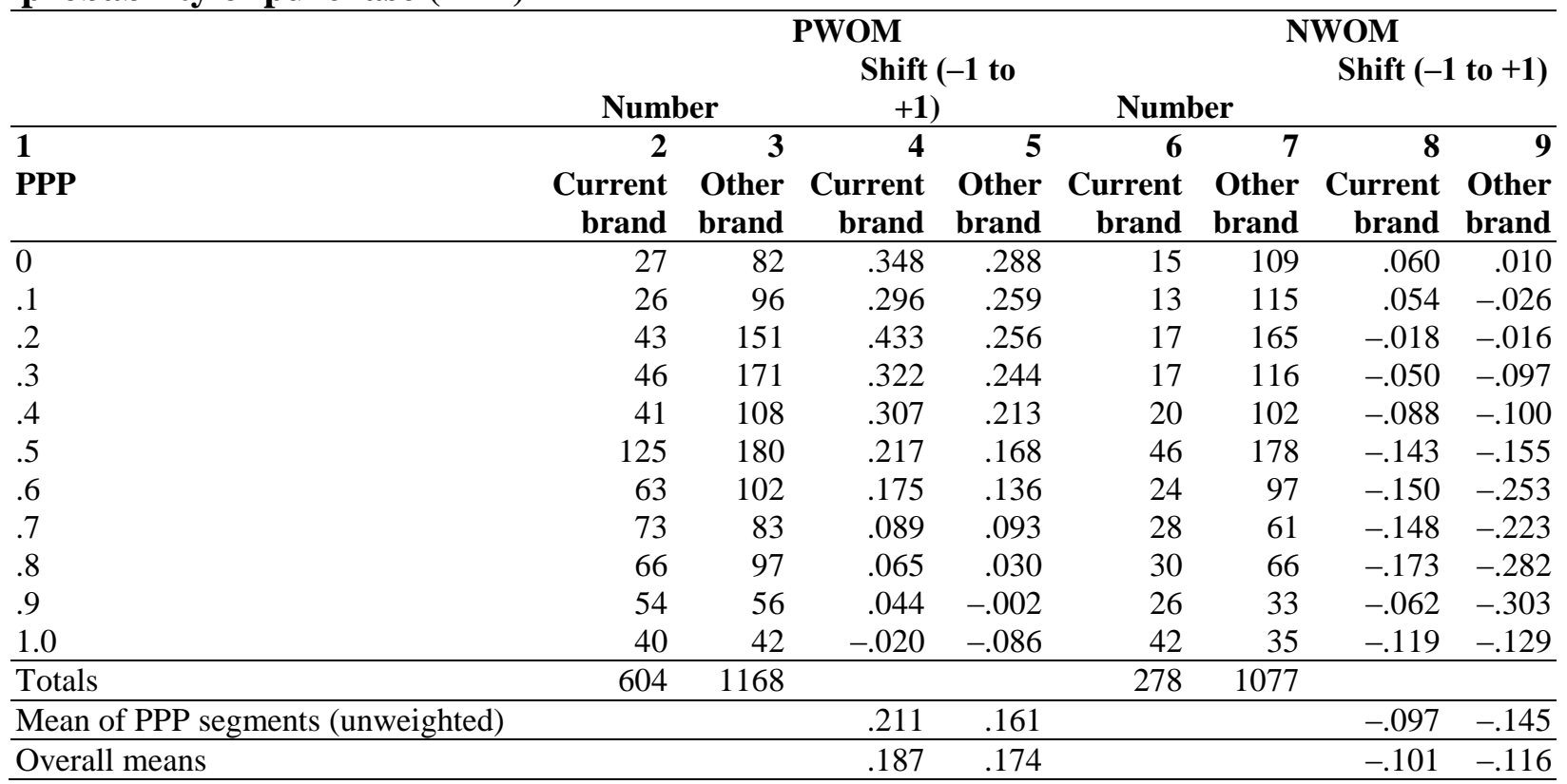

Table 2 also shows the means of the PPP segment averages in the penultimate row; these means show an impact ratio of 0.211/0.161, giving PWOM 31 percent more effect on current brands than other brands. For NWOM, this analysis shows that there is 49 percent more impact of NWOM on other brands than current brands $(-0.145 /-0.097)$. These findings approximate to the relative impact of PWOM and NWOM when the effect of prior probability is removed.

Columns 2 and 3 of Table 2 show the numbers of respondents in each PPP segment for PWOM. Inspection of these numbers shows that the current-to-other-brand ratio increases from a PPP of 0.3. Overall, the upward trend in this ratio is significant $(\mathrm{p}=.001)$. Columns 6 and 7 show corresponding numbers of respondents in each PPP segment for NWOM. Again, the ratio of current-to-other-brand numbers increases with the PPP though the trend is slight until the PPP reaches 0.6. This trend is significant $(\mathrm{p}<.001)$. Thus, those with a high probability of purchase are more likely to be current customers.

RQ1. Across the range of prior probabilities of purchase, how much do (re)purchase probabilities shift when people receive PWOM and NWOM on their current brand and on other brands?

Figures 1 (PWOM) and 2 (NWOM) illustrate how these shifts are distributed by prior probability, using the data from Table 2. Comparison of the plots in Figure 1 shows that 
PWOM has a greater impact on the current brand than other brands $(t=3.7, p=0.004)$; this effect persists when the PPP is low. Correspondingly, Figure 2 shows that NWOM on other brands has greater impact across the range of prior probabilities compared to its effect on the current brand and the overall effect is significant $(\mathrm{t}=3.2, \mathrm{p}=0.01)$; the effect of NWOM on the current brand is not enhanced when the PPP is low. Figure 1 shows how the impact of PWOM on current and other brands declines as the prior probability increases and leaves less room for change. Similarly, Figure 2 shows how the impact of NWOM increases as the prior probability increases and leaves more room for change. In neither case is there much evidence of a curvilinear effect. Thus, we do not see evidence that those with a low PPP give disproportionately less weight PWOM and more weight to NWOM as would be expected if the impact of PWOM was moderated by preference. There is some effect showing that PWOM on the current brand is somewhat discounted when the brand is unlikely to be purchased and an effect for both current and other brands indicates that NWOM is appreciably discounted when the intention to purchase is very high. East et al. (2008) described these as "commitment effects". There is no sign of curvature at the other ends of the plots.

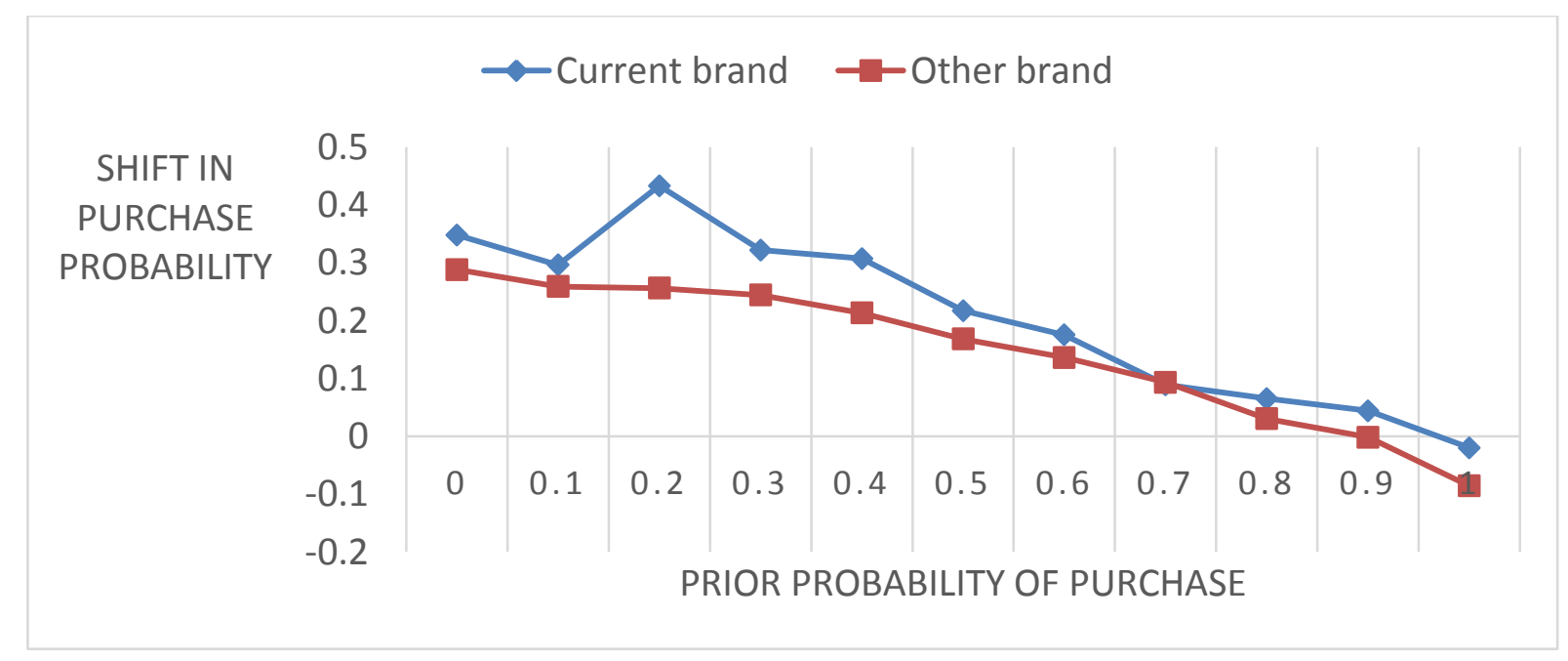

Figure 1. PWOM: Shifts in probability of purchase by prior probability 


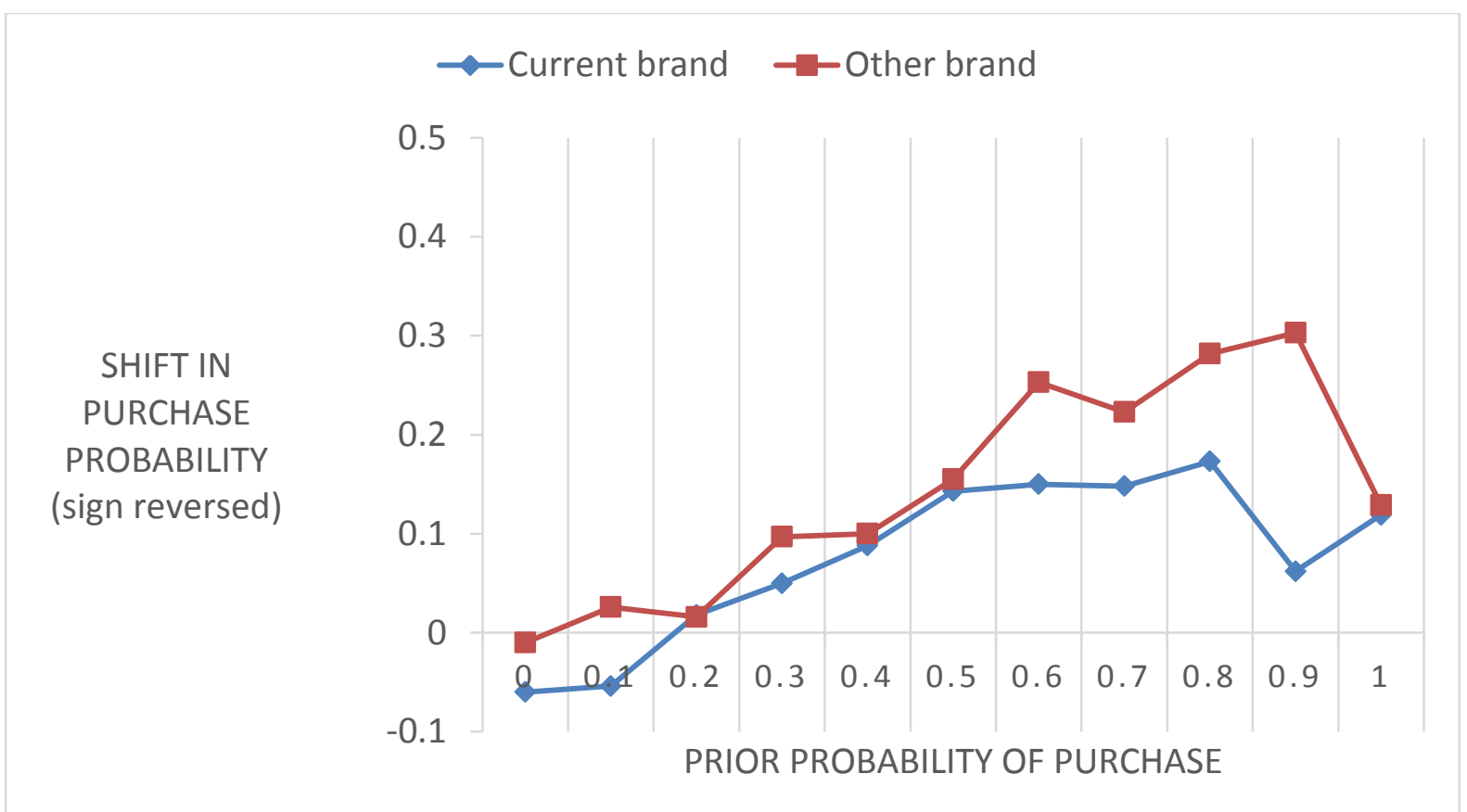

Figure 2: NWOM: Shifts in probability of purchase by prior probability (Sign reversed)

RQ2. What is the effect of PWOM and NWOM on acquiring and retaining customers?

Here, we use the numbers in the Totals row of Table 2 together with the overall mean impacts to make estimates of the relative contribution of PWOM and NWOM to customer retention and acquisition. For PWOM, we have $604 \times 0.187=113$ for retention and $1168 \times 0.174=203$ for acquisition so PWOM has approximately twice as much effect in recruiting new customers as it does in retaining existing customers. For NWOM, we have $278(-0.101)=-28$ for reducing retention and $1077(-0.116)=-125$ for reducing acquisition so NWOM has over four times as much effect in deterring people from buying new brands as it has in deterring people from re-buying current brands.

\section{Discussion}

Factors relating to impact

This research compares the impact of PWOM and NWOM when this advice is about the receiver's currently used brand and when it is about another brand. We find that, when the advice is on their current brand, people shift their purchase intention somewhat more in response to PWOM and somewhat less in response to NWOM compared with advice on other brands and that these effects are extended across the range of prior purchase probabilities. Our findings average across categories; individual categories may show rather different effects but we had insufficient data to examine each category separately. Practitioners should 
take account of this limitation and should work with data on their own category, as well as benchmarking against averages across categories, when deciding how to support their brands.

Although we find that people respond more to PWOM and less to NWOM on their current brand, it is difficult to explain this as a preference effect since the responses to PWOM and NWOM are linear across much of the range of prior probabilities of repurchase and a preference effect would have produced a curvilinear pattern. Only at one end of the plots is there evidence for an effect of preference; here, preference is associated with discounting NWOM on a brand that is very likely to be purchased and discounting PWOM on a brand that is very unlikely to be purchased. Thus, our evidence indicates a response to advice over much of the range that is not affected by preference. However, we must explain the difference in the response to WOM when current and other brands are compared. This indicates that people are more open to influence from PWOM and less open to influence from NWOM when it is on their current brand. To account for this, we suggest that experience establishes more knowledge about the brand and this affects the interpretation of WOM. Greater knowledge makes it easier to accommodate PWOM and to dismiss NWOM on the current brand. This as a working hypothesis rather than a fully supported explanation for our findings. We have inferred rather than measured experience but it seems a likely candidate and we are unable to suggest any other variables that could have produced the findings reported here.

\section{Bias in survey research}

This evidence shows that survey researchers may be able to discount some suggestions that their findings are biased by preference. In many fields of inquiry, such as WOM, survey evidence is an important way of gaining understanding so that evidence on the factors that raise or lower response is needed. The present study indicates that any differences in respondent estimates of purchase probability are not easily attributed to preference except in the extreme cases noted. Our evidence suggests that we should look again at the basis for what is called the affect heuristic (Slovic, Finucane, Peters and MacGregor, 2002). This may be partly based on frequency of experience which is usually correlated with liking. Frequency of experience is the basis of other known biases such as the availability heuristic and the tendency to support the status quo (Tversky and Kahneman 1980). 


\section{The influence on retention and acquisition}

In this work, we have estimated the contributions of PWOM and NWOM to customer acquisition and retention. About a third of the effect of PWOM is to boost retention; this retention effect is interesting since PWOM is normally seen only as a means of acquiring new customers. Turning to NWOM, we estimate that it has about four times more effect in deterring new buyers from purchasing than current buyers, so its main effect is against customer acquisition. This suggests an interesting effect with regard to new products. NWOM is mostly produced by ex-buyers of a brand (East, Romaniuk and Lomax, 2011) which means that new products tend to get less NWOM initially because they have no exbuyers. Thus, the acceptance of a new product will be assisted at first by a lack of NWOM but later this advantage will fall away as adopters start to defect. This evidence on the effects of PWOM and NWOM should also be related to their relative volume. East, Hammond and Wright. (2007) found that there is approximately three times as much PWOM as NWOM which reduces the overall effect of NWOM. We must also qualify the findings on the acquisition and retention effects of WOM because some of our categories were in repertoire fields where consumers buy more than one brand. In this work, the main brand in repertoire categories is treated as the current brand and some brands classed as "other" may be current secondary purchases so that an increased probability of purchase may not be seen as customer acquisition. This suggests that the retention effect of PWOM is greater than our estimate.

We relate this work to the important question of how brands grow and therefore what techniques should be used to stimulate this growth. Two influential books on brand growth indicate that this occurs mainly by acquiring new customers and not by increasing the amount bought by existing customers (Sharp 2010, Romaniuk and Sharp 2016). Sharp cites Baldinger, Blair, and Echambadi (2002) and draws on Ehrenberg's (1988) extensive research on consumer behaviour which shows much more variability in penetration than purchase frequency, favouring strategies designed to increase penetration. Recent work has also emphasized the way growth occurs through customer acquisition (Riebe, Wright, Stern and Sharp 2014, Romaniuk, Dawes and Nenycz-Thiel 2014). If this approach is correct, we need to know how different methods contribute to customer acquisition. Here we find that PWOM works mainly as a means of recruiting new customers and thus should be fostered but NWOM frustrates this purpose, making it a major hazard to brand growth. 


\section{References}

Baldinger, A.L., Blair, E. and Echambadi, R. (2002). Why brands grow, Journal of Advertising Research 42(1), 7-14.

Chandon, P., Morwitz, V.G. and Reinartz, W.J. (2005). Do intentions really predict behavior? Self-Generated validity effects in survey research, Journal of Marketing, 69(2), 1-14.

Chawdhary, R and Riley, F.D. (2015). Investigating the consequences of word of mouth from a WOM sender's perspective in the services context, Journal of Marketing Management, 31(9/10), 1018-1039.

Dowling, G.R. and Uncles, M.D. (1997). Do customer loyalty programs really work? Sloan Management Review, 38 (4) (Summer), 71-82.

East, R., Hammond, K., and Gendall, P. (2006). Fact and fallacy in retention marketing, Journal of Marketing Management, 22(1-2), 5-23.

East, R., Hammond, K. and Lomax, W. (2008). Measuring the impact of positive and negative word of mouth on brand purchase probability, International Journal of Research in Marketing, 25(3), 215-224.

East, R., Hammond, K. and Wright, M. (2007). The relative incidence of positive and negative word of mouth: A multi-category study, International Journal of Research in Marketing, 24(2), 175-184.

East, R., Romaniuk, J., and Lomax, W. (2011). The prediction of brand performance from word-of-mouth and satisfaction measures, The International Journal of Market Research, 53(3), 327-346.

East, R., Uncles, M., Romaniuk, J. and Hand, C. 2013). Distortions in retrospective word-ofmouth measurement, International Journal of Market Research, 55(4), 477-486.

Ehrenberg, A.S.C. (1988). Repeat Buying: Theory and Applications (2nd ed), London: Charles Griffin \& Co. (first published in 1972 by North Holland).

Ehrenberg, A.S.C., Uncles, M.D. and Goodhardt, G.J. (2004). Understanding brand performance measures: Using Dirichlet benchmarks, Journal of Business Research, 57 (12), 1307-1325.

Garnefeld, I., Eggert, A., Helm, S.V. and Tax, S.S. (2013). Growing existing customers' revenue streams through customer referral programs, Journal of Marketing, 77 (4), 17-32.

Kahneman, D., Knetsch, J., and Thaler, R. (1991). Anomalies: the endowment effect, loss aversion, and status quo bias, Journal of Economic Perspectives, 5(1), 193-206. Reprinted in D. Kahneman and A. Tversky (2000) Choices, Values, and Frames, New York: Russell Sage Foundation, Cambridge University Press, 159-170.

Keaveney, S.M. (1995). Customer switching behavior in service industries: an exploratory study, Journal of Marketing, 59(2), 71-82.

Keller Fay Agency (2014). http://www.kellerfay.com/category/blog/

Peterson, R.A. and Wilson, W.R. (1992). Measuring customer satisfaction: fact or artifact, Journal of the Academy of Marketing Science, 20(1), 61-71.

Reinartz, W. and Kumar, V. (2000). On the profitability of long-life customers in a noncontractual setting: an empirical investigation and implications for marketing, Journal of Marketing, 64(4), 17-36.

Riebe, E., M. Wright, P. Stern and B. Sharp (2014). How to grow a brand: Retain or acquire customers? Journal of Business Research, 67(5): 990-997.

Reichheld, F.F. and Teal, T. (1996). The Loyalty Effect. Boston: Harvard Business School Publications.

Romaniuk, J., J. Dawes and M. Nenycz-Thiel (2014). Generalizations regarding the growth and decline of manufacturer and store brands, Journal of Retailing and Consumer Services, 21(5): 725-734.

Romaniuk, J. and B. Sharp (2016). How Brands Grow, Part 2, Melbourne: Oxford. 
Sharp, B. (2010). How Brands Grow, Melbourne: Oxford.

Slovic, P., Finucane, M., Peters, E., and MacGregor, D.G. (2002). Rational actors or rational fools: Implications of the affect heuristic for behavioral economics, Journal of SocioEconomics, 31(4), 329-42.

Tversky, A. and Kahneman, D. (1980). Causal schemas in judgements under uncertainty, Progress in Social Psychology, 1, 49-72.

Uncles, M.D., East, R. and Lomax, W. (2013). Good customers: The value of customers by mode of acquisition, Australasian Marketing Journal, 21 (2), 119-125. 